\title{
A Test of the Cytosolic Apolipoprotein E Hypothesis Fails to Detect the Escape of Apolipoprotein E from the Endocytic Pathway into the Cytosol and Shows that Direct Expression of Apolipoprotein E in the Cytosol is Cytotoxic
}

\author{
Ronald B. DeMattos, Fayanne E. Thorngate, and David L. Williams \\ Department of Pharmacological Sciences, University Medical Center, State University of New York at Stony Brook, Stony \\ Brook, New York 11794
}

Genetic evidence indicates that apolipoprotein E4 (apoE4) is a risk factor for the development of Alzheimer's disease. A controversial hypothesis proposes that apoE, a typical secretory protein, accesses the neuronal cytosol in which apoE3, but not apoE4, protects tau from hyperphosphorylation. However, no conclusive evidence for the presence of apoE in the cytosolic compartment has been presented. We designed a novel assay to test whether apoE can access the cytosol via escape from the endocytic pathway by incorporating a nuclear localization signal (NLS) into apoE. Control experiments demonstrated that apoE plus NLS (apoE+NLS) is chaperoned to the nucleus if it

Apolipoprotein E (apoE) is a secretory protein that plays a major role in cholesterol homeostasis in the plasma (Weisgraber, 1994). ApoE is an atypical apolipoprotein in that it is produced by many extrahepatic tissues (Blue et al., 1983), most notably the brain (Elshourbagy et al., 1985; Newman et al., 1985; Williams et al., 1985; Rea et al., 1993) in which it is secreted by astrocytes and microglial cells (Boyles et al., 1985; Pitas et al., 1987a; Nakai et al., 1996; Stone et al., 1997). The finding that apoE secretion increases in response to nerve damage (Dawson et al., 1986; Ignatius et al., 1986; Snipes et al., 1986; Boyles et al., 1990) has led to proposals that apoE plays a role in neuronal repair and remodeling.

There are three common isoforms of apoE arising from single amino acid interchanges at positions 112 and 158 (Zannis et al., 1982). Recently, the $\epsilon 4$ allele of apoE has been identified as a risk factor for the development of late-onset familial and sporadic Alzheimer's disease (AD) (Rebeck et al., 1993; Strittmatter et al., 1993a, 1994b; Goedert et al., 1994). The biochemical basis for this correlation is unknown. The pathologies of $\mathrm{AD}$ manifest in two very different locales; amylidosis is an extracellular event, whereas neurofibrillary tangles are initiated intracellularly (Mirra et al., 1991). In vitro experiments demonstrate that apoE interacts

Received Nov. 17, 1998; revised Jan. 11, 1999; accepted Jan. 19, 1999.

This work was supported by National Institutes of Health, National Heart, Lung, and Blood Institute Grant HL 32868. R.B.D. was partially supported by a predoctoral fellowship from the Institute for Cell and Developmental Biology, State University of New York at Stony Brook. F.E.T. was partially supported by Institutional National Research Award IT32-DK-07521. We thank Miguel Berrios and William Theurkauf for advice on confocal microscopy and Joel Levine for helpful discussion.

Correspondence should be addressed to David L. Williams, Department of Pharmacological Sciences, University Medical Center, State University of New York at Stony Brook, Stony Brook, NY 11794.

Copyright (C) 1999 Society for Neuroscience $\quad 0270-6474 / 99 / 192464-10 \$ 05.00 / 0$ reaches the cytosolic compartment. When exogenous apoE+NLS was endocytosed by neuronal cells, no nuclear apoE was detected, indicating that apoE remains within the endocytic pathway and does not escape into the cytosol. Furthermore, we show that direct cytosolic expression of apoE is cytotoxic. These data argue that effects of apoE on the neuronal cytoskeleton and on neurite outgrowth are not mediated via cytosolic interactions but rather by actions originating at the cell surface.

Key words: Alzheimer's disease; apoE; cytosolic; cytotoxic; endocytosis; microtubules; nuclear localization assay; tau

isoform-specifically with the primary constituents of each of these pathologies. Several groups have shown isoform-specific binding of the amyloid $\beta$ peptide to apoE (Strittmatter et al., 1993a,b; LaDu et al., 1994, 1995). Strittmatter et al. (1994a) have shown in vitro that apoE3 binds tightly to the microtubule-stabilizing protein tau, whereas apoE4 does not. Additionally, apoE3, but not apoE4, can stimulate neurite outgrowth in a variety of culture systems (Nathan et al., 1994, 1995; Holtzman et al., 1995; DeMattos et al., 1998; Sun et al., 1998).

A model was proposed that links the apoE isoform-specific observations to the development of AD (Strittmatter et al., 1994b). This model requires that apoE3 access the cytosol to bind to tau and shield it from hyperphosphorylation, thereby preventing the development of neurofibrillary tangles. Supporting data consists of the apoE-tau interactions noted above and immunocytochemical findings in neurons from brain tissue and neuronal cells in culture (Han et al., 1994; Strittmatter et al., 1994b; Nathan et al., 1995; Metzger et al., 1996). These studies show intracellular apoE but fail to discriminate between apoE that is cytosolic as opposed to apoE within vesicles of the endosomal-lysosomal pathway.

In the present study, we developed a novel assay to determine the location of apoE within neuronal cells by using the nuclear localization pathway to distinguish between apoE that is enclosed by membranes (endosomal-lysosomal) or truly cytosolic. This protein sorting system has only two requirements: first, the protein that is to be transported to the nucleus must contain a recognizable nuclear localization signal (NLS), and second, the protein must be in the cytosol (Roberts et al., 1987; Dingwall and Laskey, 1991; Silver, 1991; Weis et al., 1995). We constructed expression vectors for wild-type apoE and apoE that has an NLS at the $\mathrm{C}$ terminus (apoE+NLS). Neuro-2a neuroblastoma cells 
(which do not make apoE but do show an apoE isoform-specific stimulation of neurite outgrowth by exogenous apoE) were incubated with apoE or apoE+NLS, and the subsequent intracellular localization was monitored. If apoE+NLS escapes from the endosomal-lysosomal pathway into the cytosol, apoE will be chaperoned to the nucleus, a subcellular compartment that is easily distinguished from other organelles. Our results show that little or no apoE reaches the cytosol, despite the active endocytic uptake of apoE into the cell. Furthermore, direct expression of apoE in the cytosol was shown to be cytotoxic. These findings argue against the hypothesis that apoE3 interacts directly with tau in the cytosol of neuronal cells.

\section{MATERIALS AND METHODS}

The establishment and characterization of an apoE expression vector series. Construction of expression vectors for wild-type and modified forms of apoE was accomplished by standard molecular cloning techniques. The four vectors shown in Table 1 were made using an apoE-specific PCR protocol, followed by replacement subcloning into the vectors $\mathrm{pC} 1 \mathrm{E} 3$ and pC1E4 (DeMattos et al., 1998). The signal peptide (SP) bypass forms of apoE were made with an upstream primer homologous to the apoE coding region for amino acids $25-30$. This primer also incorporated a start codon that conforms to the Kozak consensus sequence (Kozak, 1986). A nuclear localization sequence of tandem PKKKRKV residues separated by three uncharged amino acids $(\mathrm{GVG})$ was incorporated into the $\mathrm{C}$-terminal end of apoE at amino acid 317 by the same technique (PCR).

Production and maintenance of stable apoE Neuro-2a cell lines. Neuro-2a cells were maintained in a $37^{\circ} \mathrm{C}$ humidified $95 \%$ air $-5 \% \mathrm{CO}_{2}$ incubator in medium A [DMEM/F-12 (1:1) supplemented with 10\% heat-inactivated fetal bovine serum (FBS) (Atlanta Biologicals), $4 \mathrm{~mm}$ glutamine, $100 \mathrm{U} / \mathrm{ml}$ penicillin, $100 \mathrm{U} / \mathrm{ml}$ streptomycin sulfate, and 0.25 $\mu \mathrm{g} / \mathrm{ml}$ amphotericin B]. Neuro-2a cells were plated at $1.0 \times 10^{6}$ cells in $10 \mathrm{ml}$ of medium A per $10 \mathrm{~cm}$ dish and were transfected with $20 \mu \mathrm{g}$ of plasmid using a standard calcium phosphate precipitation protocol (Chen and Okayama, 1987). Stable integrants were selected and maintained in medium B [medium A plus $350 \mu \mathrm{g} / \mathrm{ml} \mathrm{G} 418$ (Life Technologies, Gaithersburg, MD)]. Northern blot analysis was conducted as described previously (DeMattos et al., 1998).

Western blotting analysis. Cells were plated at $1.0 \times 10^{7}$ cells in $10 \mathrm{ml}$ of medium A per $10 \mathrm{~cm}$ dish, incubated overnight at $37^{\circ} \mathrm{C}$, washed twice with medium A, and incubated for an additional $24 \mathrm{hr}$ in $10 \mathrm{ml}$ of fresh medium A. Conditioned medium was removed, and cells were washed two times with PBS and solubilized in $0.5 \mathrm{ml}$ of $2 \%$ SDS in PBS for total protein determination. Conditioned medium and cell lysates $(100 \mu \mathrm{g})$ were run on a $10 \%$ polyacrylamide-SDS gel, electrophoretically transferred to nitrocellulose, and blocked for $1 \mathrm{hr}$ at room temperature in TBS (20 mM Tris-HCl, pH 7.4, and $150 \mathrm{~mm} \mathrm{NaCl}$ ) containing $7 \%$ nonfat milk and $0.05 \%$ Tween 20 . The blocked membrane was incubated with affinity-purified polyclonal goat anti-human apoE antibody (BioDesign International, Kennebunk, ME) at $2 \mu \mathrm{g} / \mathrm{ml}$ overnight at room temperature in TBS containing $1 \%$ nonfat milk and $0.2 \%$ Tween 20 . The membrane was washed three times with TBS containing $0.05 \%$ Tween 20 and incubated with a horseradish peroxidase-conjugated anti-goat IgG (Sigma, St. Louis, MO) for $1 \mathrm{hr}$ at room temperature in TBS containing $1 \%$ nonfat milk and $0.05 \%$ Tween 20 . Bands were visualized by enhanced chemiluminescence (Amersham, Arlington Heights, IL).

Stable transfection efficiency assay. Stable transfection efficiencies were determined by transfecting $1.0 \times 10^{6}$ Neuro-2a cells in $10 \mathrm{~cm}$ dishes with $20 \mu \mathrm{g}$ of plasmid coding for either secreted apoE or intracellular apoE. Stable integrants were selected for 9-12 d with $350 \mu \mathrm{g} / \mathrm{ml} \mathrm{G418} \mathrm{(Life}$

Table 1. Apolipoprotein E expression vectors

\begin{tabular}{lll} 
Constructs & Initial cellular location & Final cellular location \\
\hline ApoE & Secretory pathway & Extracellular \\
ApoE + NLS & Secretory pathway & Extracellular \\
ApoE - SP & Cytosol & Cytosol \\
ApoE + NLS - SP & Cytosol & Nuclear \\
\hline
\end{tabular}

Technologies). Plates were washed three times with PBS, and the cells were fixed with $2.5 \%$ glutaraldehyde, permeabilized with $1 \%$ Triton $\mathrm{X}-100$, and stained with ethidium bromide. Images were collected with a UV transilluminator with a video camera attachment (Ultra-Violet Products, Upland, CA) and were saved as tagged image file format files. The number of cell colonies per image was determined with the UTHSCSA Image Tool program (developed at the University of Texas Health Science Center at San Antonio, Texas and available from the internet by anonymous file transfer protocol from ftp:maxrad6.uthscsa.edu) The experiment was repeated with three different plasmid preparations.

ApoE immunocytochemistry. Neuro-2a stable cell lines and transiently transfected cells were analyzed for apoE immunocytochemistry as described previously (DeMattos et al., 1998). Nuclei isolated as described below were fixed with $3 \%$ paraformaldehyde-PBS and $0.1 \%$ glutaraldehyde for $15 \mathrm{~min}$ on ice. The nuclei were permeabilized with $0.5 \%$ Triton X-100-PBS (PBST) for 15 min on ice, and residual glutaraldehyde was quenched with $50 \mathrm{~mm}$ ammonium chloride in PBST. Nuclei were incubated with an affinity-purified polyclonal goat anti-human apoE antibody (BioDesign International) at $2 \mu \mathrm{g} / \mathrm{ml}$ in PBST containing 1\% FBS for 1 hr at $37^{\circ} \mathrm{C}$. The nuclei were washed three times with PBST and incubated with a rhodamine-conjugated donkey anti-goat IgG antibody (Jackson ImmunoResearch, West Grove, PA) at 1:2000 in PBST containing 1\% FBS for $1 \mathrm{hr}$ at $37^{\circ} \mathrm{C}$. Nuclei were washed three times with PBST, mounted in SlowFade (Molecular Probes, Eugene, OR), and analyzed with a Bio-Rad (Hercules, CA) MR-600 scanning confocal system mounted on a Nikon (Tokyo, Japan) Diaphot inverted microscope. The intracellular localization of apoE3 or apoE3+NLS lipoproteins was determined by incubating Neuro-2a cells with apoE disks $(2.5 \mu \mathrm{g} / \mathrm{ml}$ for apoE3 or $250 \mathrm{ng} / \mathrm{ml}$ for apoE3+NLS) for $4 \mathrm{hr}$ at $37^{\circ} \mathrm{C}$. The cells were then processed as stated above.

Transient Neuro-2a transfections. Transient apoE expression for Western blot analysis was accomplished by transfecting $1.0 \times 10^{6}$ cells per 10 $\mathrm{cm}$ dish with $20 \mu \mathrm{g}$ of plasmid and analyzing the cells after $12 \mathrm{hr}$ for apoE expression. Neuro-2a cells were plated onto $18 \mathrm{~mm}$ glass circle coverslips in 12-well tissue culture plates at a density of $8.0 \times 10^{4}$ cells per well and were subsequently transfected with $1 \mu \mathrm{g}$ of plasmid. After $12 \mathrm{hr}$ of expression, the cells were analyzed by apoE immunocytochemistry.

ApoE and apoE $+N L S$ isolation and association with lipids. Neuro-2a cells secreting either apoE or apoE+NLS were grown to confluence in T175 flasks. Serum free media (DMEM/F-12, 1:1) was conditioned for $24 \mathrm{hr}$ for either cell line. The conditioned media was passed through a D100 weakly basic anion exchange filter (Satorius) and apoE eluted with $1 \mathrm{M}$ ammonium bicarbonate. The eluted apoE was diluted 10 -fold with sterile distilled water and recirculated over HiTrap heparin columns (Pharmacia, Piscataway, NJ). The heparin-bound apoE or apoE+NLS was eluted with $1 \mathrm{~m}$ ammonium bicarbonate. Fractions containing apoE were pooled and dialyzed against PBS (this fraction is referred to as lipid-poor apoE). ApoE dimyristoyl-phosphatidylcholine (Sigma) disks were prepared as described previously (Innerarity et al., 1979). ApoE- $\beta$ very low-density lipoprotein ( $\beta \mathrm{VLDL}$ ) was prepared by incubating concentrated media from either cell line with plasma from apoE knock-out mice for $2.5 \mathrm{hr}$ at $4^{\circ} \mathrm{C}$. The apoE- $\beta$ VLDL lipoproteins were then isolated by ultracentrifugation. Mouse $\beta$ VLDL from apoE knock-out mice was prepared by standard methods (Kelly and Kruski, 1986).

The nuclear localization assay. Neuro-2a cells were plated at $1.0 \times 10^{6}$ cells per $60 \mathrm{~mm}$ dish in complete medium (DMEM/F-12, 1:1, plus $10 \%$ FBS). After $24 \mathrm{hr}$, the medium was changed to N2 medium [DMEM/F12, 1:1, plus N2 growth supplements (Life Technologies) (Bottenstein and Sato, 1979)], and the cells were incubated at $37^{\circ} \mathrm{C}$ for an additional $16 \mathrm{hr}$. The medium was changed to N2 medium alone or N2 medium containing either apoE3 or apoE3 + NLS lipoproteins, and the cells were incubated at $37^{\circ} \mathrm{C}$ for $4 \mathrm{hr}$. Each experimental condition was run in duplicate. At the conclusion of the assay, the media was removed and saved for apoE ELISA determination. The dishes were washed three times with prewarmed $\mathrm{PBS}\left(37^{\circ} \mathrm{C}\right)$ and trypsinized for $2 \mathrm{~min}$ (to remove extracellularly bound apoE). The cells were transferred to $1.5 \mathrm{ml}$ tubes on ice, and the trypsin was neutralized with chilled complete medium. Cells were washed twice with complete medium and then twice with ice-cold buffer A (10 mM Tris-HCl, $\mathrm{pH} 7.4,3 \mathrm{~mm} \mathrm{CaCl} 2,2 \mathrm{~mm} \mathrm{MgCl}_{2}$, and $0.1 \mu \mathrm{g} / \mathrm{ml}$ PMSF). Cytoplasmic extracts were isolated by incubating the cells on ice in buffer A plus $0.5 \%$ NP-40 (Particle Data Group, Berkeley, CA) for 5 min with occasional pipetting up and down with a large bore pipette. The extracts were spun for $2 \mathrm{~min}$ at $2000 \mathrm{rpm}$ in a microcentrifuge, and the supernatant was transferred to a fresh tube on ice (cytoplasmic fraction). The nuclei in the pellet were washed twice 
$\mathbf{A}$

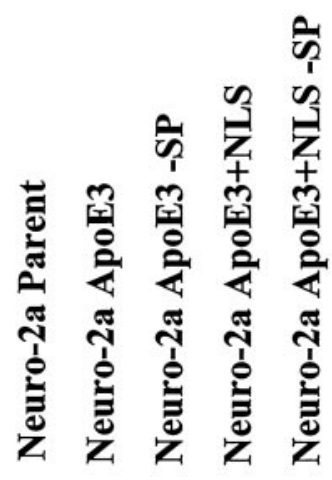

B
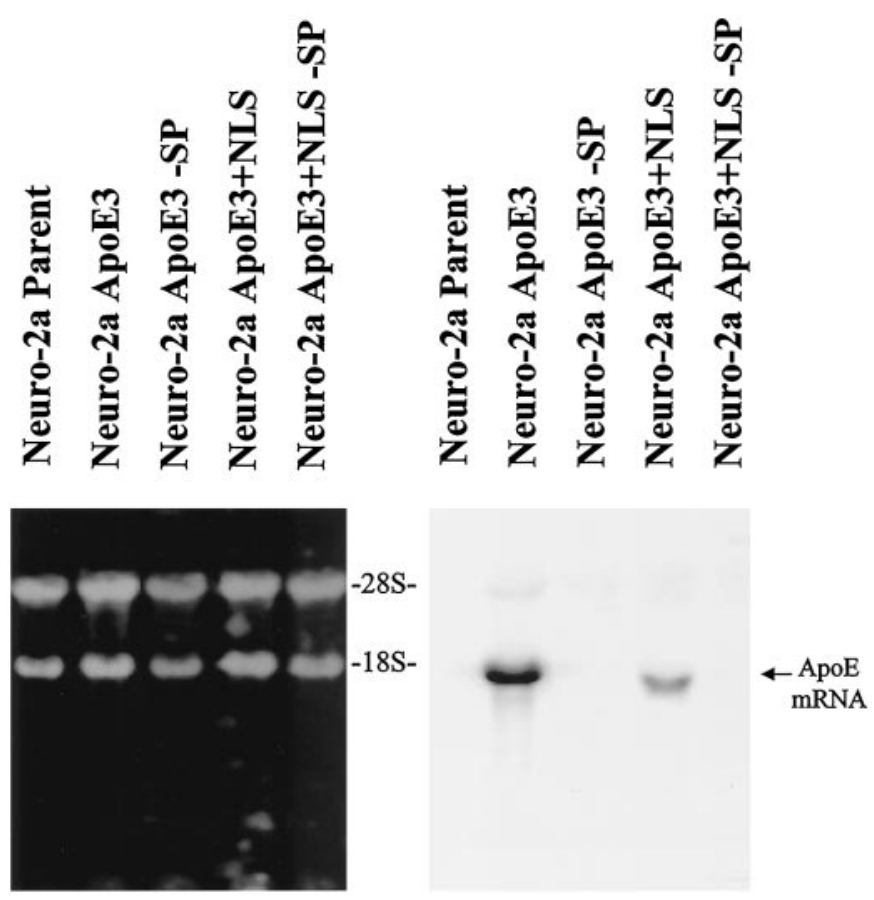

Figure 1. Northern blot of apoE mRNA in stably transfected cell lines. Total RNA ( $25 \mu \mathrm{g} /$ lane) prepared from the indicated Neuro-2a cell lines was denatured and separated by electrophoresis on a $1.2 \%$ formaldehydeagarose gel. After transfer to a nylon membrane, the RNA was visualized by ethidium bromide staining to verify that equal amounts of intact RNA were present $(A)$. The membrane was probed with a ${ }^{32} \mathrm{P}$-labeled random primed apoE fragment (nucleotides 209-653), and hybridization was visualized with a Molecular Dynamics (Sunnyvale, CA) PhosphorImager (B).

with buffer A plus $0.5 \%$ NP-40. The nuclei were fractured by sonication in buffer A plus $0.5 \%$ NP-40. The protein concentration was determined (Lowry et al., 1951) for the cytoplasmic fractions, and an ELISA was performed to measure apoE concentration in both the cytoplasmic and nuclear fractions (DeMattos et al., 1998).

\section{RESULTS}

\section{The nuclear localization assay}

The inherent limitations of immunocytochemical studies make it difficult to discern whether apoE observed in neurons is membrane-enclosed within the endosomal-lysosomal pathway or actually free in the cytosol. The nuclear localization assay allows us to characterize the intracellular location of apoE by using an active pathway that can only sort ligands to the nucleus if they are present in the cytosol. We constructed expression plasmids coding for wild-type apoE and for apoE +NLS by PCR. Wild-type apoE3 and apoE3 + NLS proteins were secreted by cells, isolated from culture medium, and added to neuronal cells for subsequent localization studies.

The site in which an NLS is incorporated into a protein may effect its recognition. An NLS can function in a variety of sites within a protein, yet in some locations it may be masked (Roberts et al., 1987). Two additional plasmids were created as controls to verify that the NLS incorporated into apoE would be recognized if the protein were in the cytosol. The first control plasmid produces apoE without the signal peptide and generates cytosolic apoE (apoE-SP) when expressed in cells. The second control plasmid also lacks a signal peptide but has a C-terminal NLS
$\mathbf{A}$

$\mathbf{B}$

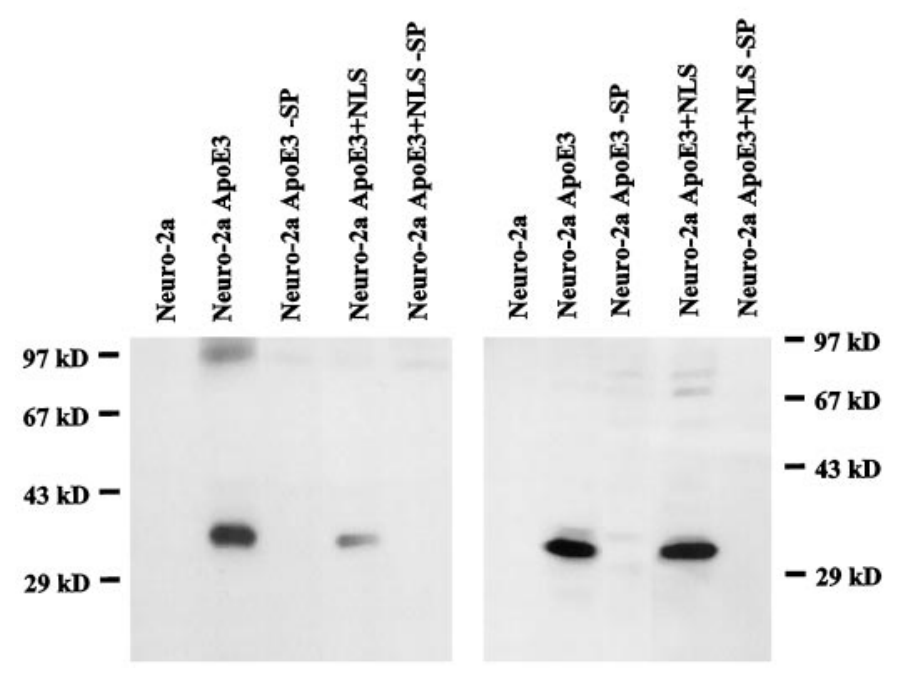

Figure 2. Western blot of apoE secreted by stably transfected cell lines. Conditioned medium $(A)$ and cytoplasmic proteins $(B)$ from the indicated cell lines (100 $\mu \mathrm{g}$ of protein/lane) were separated by $10 \%$ SDS-PAGE and were electroblotted to a nitrocellulose membrane. The membrane was probed with an affinity-purified polyclonal goat anti-human apoE antibody, and bands were visualized by enhanced chemiluminescence.

(apoE+NLS-SP). Messenger RNA from this plasmid will be translated in the cytosol on free ribosomes, and if the incorporated NLS is recognizable, the newly made protein will be chaperoned to the nucleus. Table 1 shows the expected cellular locations of the proteins from each of these plasmids when they are expressed in mammalian cells. The signal peptide bypass apoE is an ideal control to visualize what a cytosolic distribution of apoE should look like by immunocytochemistry.

\section{Cytosolic apoE is toxic}

Neuro-2a cells were transfected with the plasmids listed in Table 1 and selected for resistance to G418. The neomycin resistance gene is present in each of the plasmids. Three clonal cell lines for each plasmid were screened for apoE expression. Northern blot analysis of apoE3 mRNA (Fig. 1) and Western blot analysis (Fig. 2) confirmed that wild-type apoE3 and apoE3+NLS were expressed and that the proteins accumulated in the culture medium. We did not detect any apoE expression for either of the signal peptide bypass plasmids (apoE-SP or apoE+NLS-SP) by Northern or Western blot (Figs. 1, 2). We also observed a tremendous disparity between the number of G418 resistant clones for the secreted apoE3 plasmids versus the signal peptide bypass apoE3 plasmids (secreted plasmids $\gg$ cytosolic plasmids). We hypothesized that the lack of expression and low clone yields was caused by a toxic effect of cytosolic apoE during the initial G418 selection period. To determine whether cytosolic apoE is cytotoxic, we measured the stable transfection efficiency for secreted apoE3 versus cytosolic apoE3 (apoE3-SP). Neuro-2a cells were transfected with plasmids coding either secreted apoE3 or cytosolic apoE3, and we counted the cell colonies present after a 9-12 d selection period. Figure 3 shows that transfection efficiency was drastically reduced with the plasmids expressing cytosolic apoE3 relative to transfections with the plasmids expressing secreted 


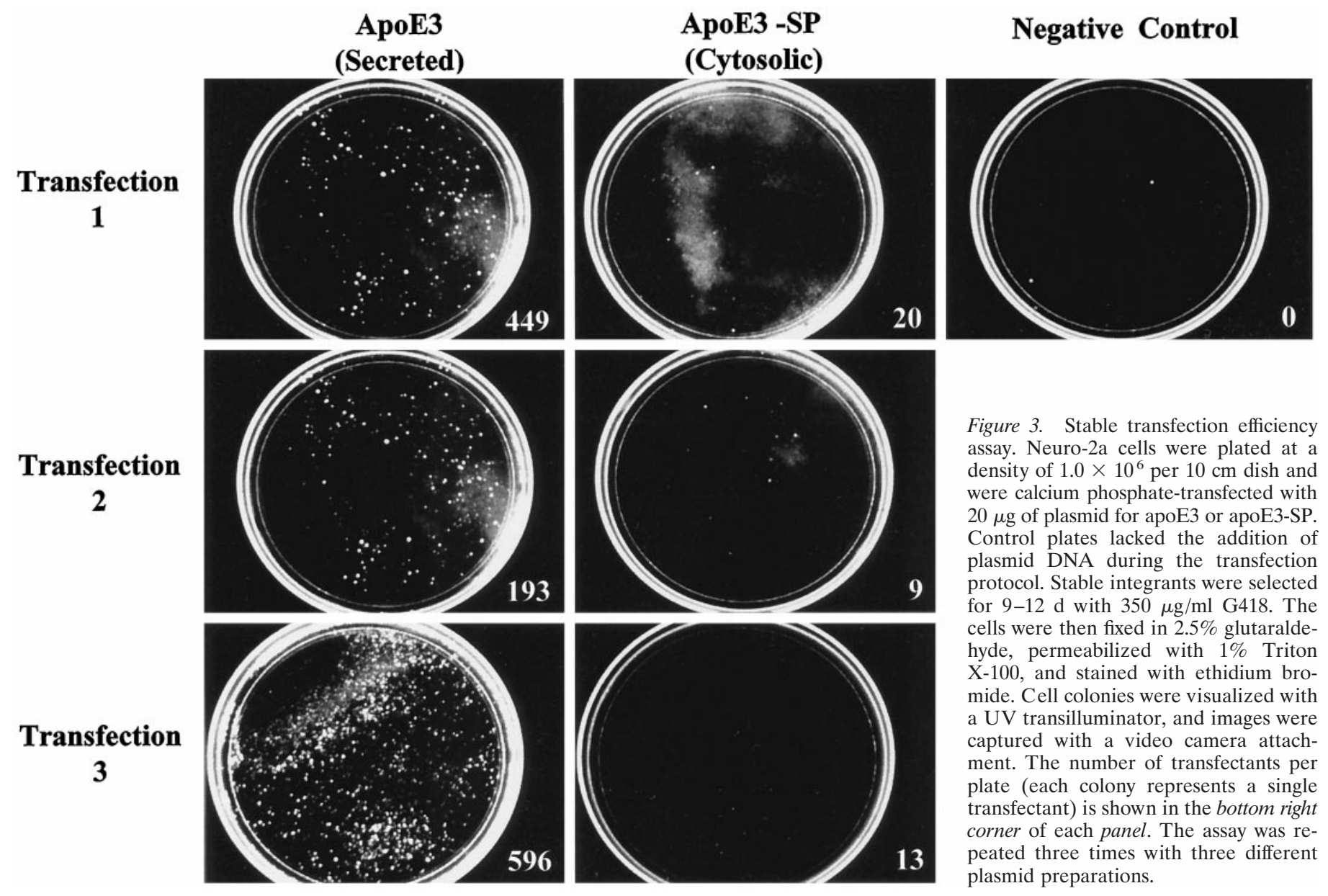

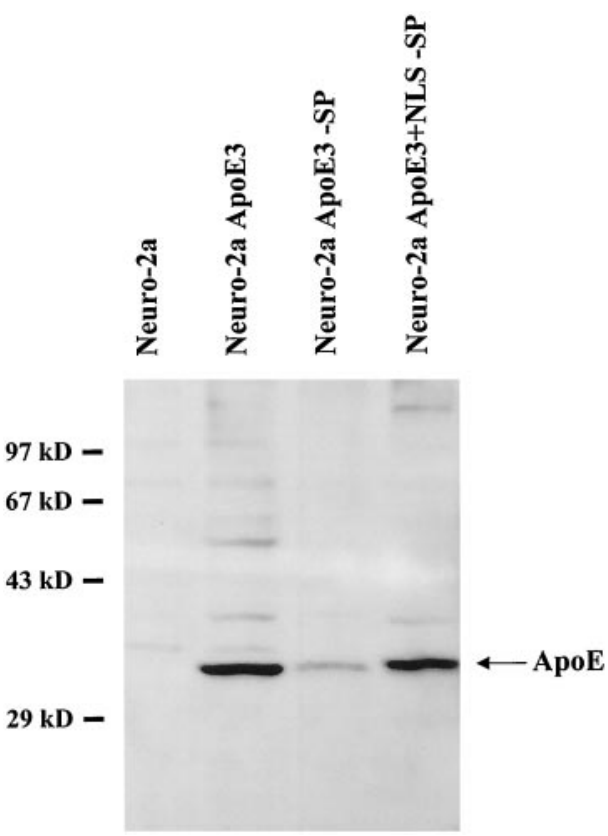

Figure 4. Western blotting of Neuro-2a cells transiently expressing apoE plasmids. Neuro-2a cells were plated at a density of $1.0 \times 10^{6}$ per $10 \mathrm{~cm}$ dish and were transfected with $20 \mu \mathrm{g}$ of plasmid for apoE3, apoE3-SP, or apoE3+NLS-SP. Cell lysates from transfected and control nontransfected Neuro-2a cells were prepared after $12 \mathrm{hr}$ of expression. Cell lysates $(100 \mu \mathrm{g})$ were analyzed for apoE by Western blotting as described in Materials and Methods.
apoE3. In three separate transfection experiments, secreted apoE3 had an average of 412 colonies as opposed to 14 colonies for the cytosolic apoE3. We demonstrated that the differences in transfection efficiency were not a reflection of DNA quality by performing the experiments with DNA from three separate plasmid isolations. Additionally, we did not detect intracellular apoE expression in cell lysates made from a pool of colonies stably transfected with the plasmid expressing apoE3 without the signal peptide. These data indicate that cytosolic apoE is toxic in Neuro-2a cells. The mechanism and threshold of the apoE cytosolic toxicity are unknown.

\section{Analysis of cytosolic apoE in transient transfection assays}

Expression of the signal peptide bypass plasmids was necessary to verify that the incorporated NLS is recognized if apoE enters the cytosolic compartment. Because stable expression of cytosolic apoE is toxic, we switched to a transient transfection assay to allow us to test for cytosolic apoE before it kills the cells. Neuro-2a cells transfected with plasmids coding for apoE3, apoE3-SP, or apoE3+NLS-SP were analyzed by an apoE Western blot $12 \mathrm{hr}$ after transfection (Fig. 4). An apoEimmunoreactive band was detected in cytoplasmic extracts of cells transiently expressing each of the apoE plasmids, thereby proving that apoE is expressed before cell death. We next analyzed the subcellular apoE distribution in transiently transfected cells by immunostaining. Neuro-2a cells expressing secreted 

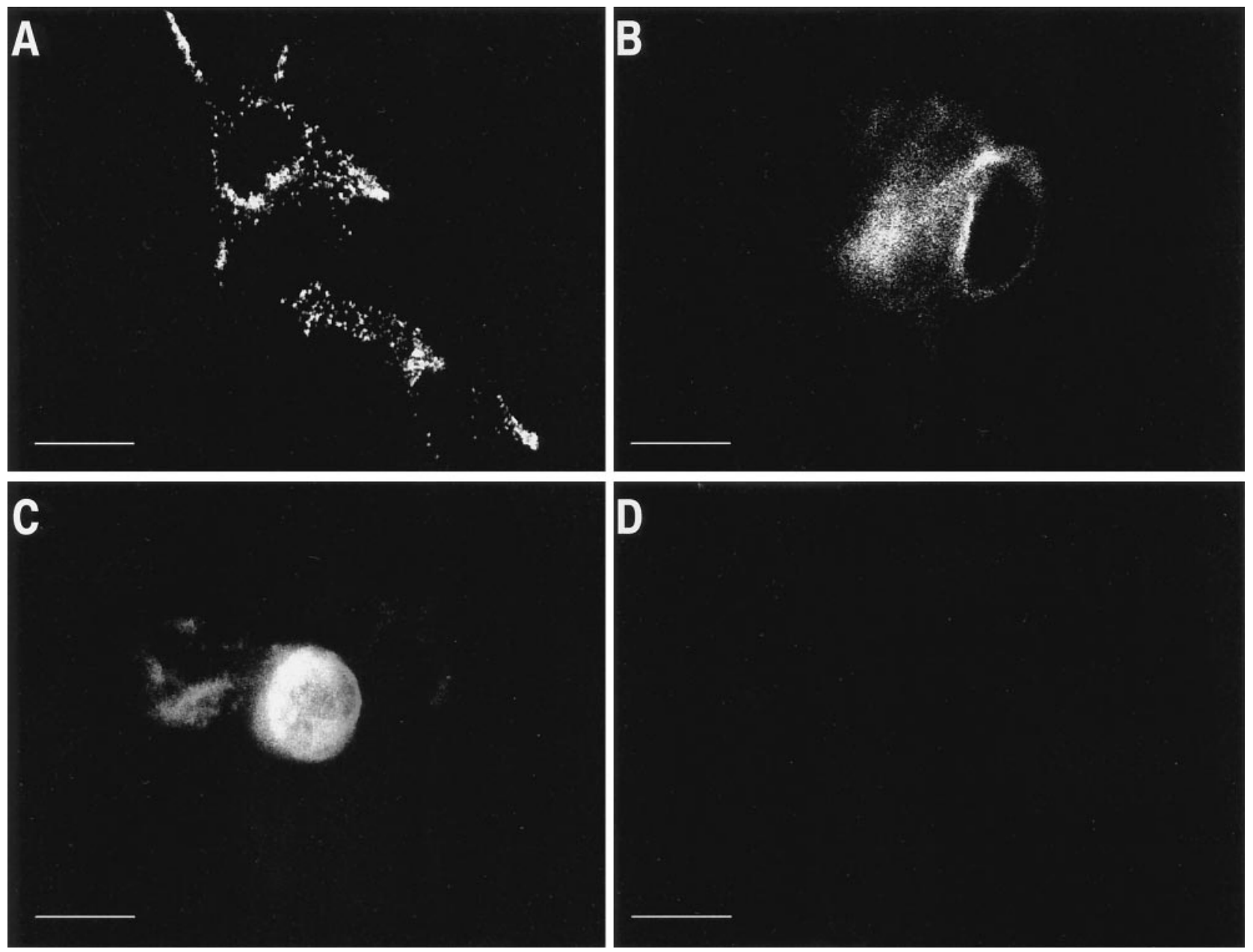

Figure 5. Immunocytochemical analysis of Neuro-2a cells transiently expressing apoE plasmids. Neuro-2a cells were analyzed by apoE immunocytochemistry after $12 \mathrm{hr}$ of expression. Cells were transfected with apoE3 $(A)$, apoE3-SP $(B)$, or apoE3+NLS-SP $(C)$. Neuro-2a cells $(D)$ were also treated with a mock transfection (no plasmid). ApoE localization was detected with an affinity-purified polyclonal goat anti-human apoE antibody and a rhodamine-conjugated secondary antibody. All images were collected by confocal microscopy with a $60 \times$ oil immersion lens. Scale bars, $10 \mu \mathrm{m}$.

apoE3 had a very intense punctate staining pattern that was characteristic of membrane-bound vesicles (Fig. 5A). Cells expressing the cytosolic apoE3 (apoE-SP) displayed a very diff use staining pattern throughout the cell (Fig. $5 B$ ). The diffuse cytosolic apoE staining is easily differentiated from the punctate staining of vesicular apoE (Fig. 5, compare $A, B$ ). Nuclei of cells expressing either secreted or cytosolic apoE3 showed no apoE staining. Expression of apoE3 + NLS-SP resulted in light apoE staining within the cytosol and a very intense apoE signal in the nucleus (Fig. 5C). The nuclear localization of apoE indicated that the NLS was recognized in the cytosol. To confirm these results, nuclei were isolated from Neuro-2a cells transiently transfected with the same plasmids as above and were analyzed by apoE immunocytochemistry (Fig. 6). Although there was a similar number of nuclei present per image, apoE-immunoreactive nuclei were only present in Neuro-2a cells that had been transiently transfected with apoE3+NLS-SP. A high-magnification view of an immunoreactive nucleus shows that apoE completely fills the nuclear space (except the presumed nucleolus). The intracellular location of apoE in transiently transfected cells was verified by apoE ELISA (data not shown). These experiments demonstrate that the cytosolic nuclear localization machinery recognizes the NLS incorporated into apoE3. If apoE3+NLS escapes from the endocytic pathway into the cytosol of the cell, it will accumulate in the nucleus.

\section{ApoE and apoE+NLS intracellular localization}

We next tested whether apoE3 or apoE3+NLS is endocytosed when added to cells. ApoE3 and apoE3+NLS were isolated by a combination of anion exchange and heparin affinity chromatography from conditioned media of transfected Neuro-2a cells. ApoE3 isolated from these cell cultures was shown previously to be poorly lipidated (DeMattos et al., 1998). We prepared particles that could be endocytosed by increasing the lipidation of apoE. Lipid-poor apoE3 or apoE3+NLS were incubated with dimyristoyl-phosphatidylcholine, and the resulting disciodal particles were isolated by density-gradient ultracentrifugation. Neuro-2a cells were incubated with either apoE3 or apoE3+NLS disks for $4 \mathrm{hr}$ and analyzed by apoE immunocytochemistry. Both apoE3 and apoE3+NLS were readily endocytosed and were localized to a perinuclear compartment that is presumably neural lysosomes (Fig. 7) (Ignatius et al., 1987). The punctate apoE fluorescence pattern in these cells is quite different from the diff use cytosolic pattern seen in Figure $5 B$. Western blot analysis of cell lysates from Neuro-2a cells incubated with either apoE3 or 

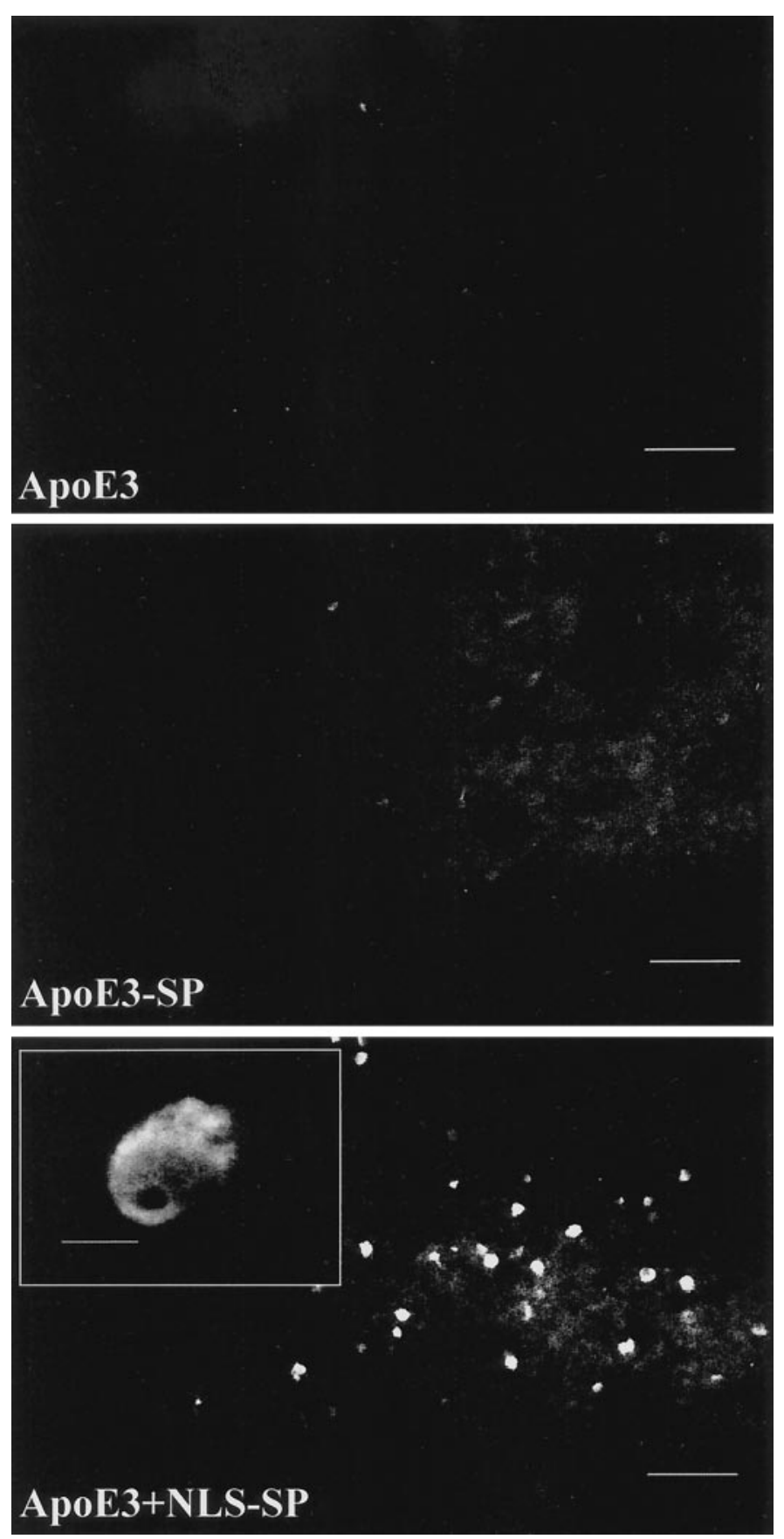

Figure 6. Immunocytochemical analysis of nuclei isolated from Neuro-2a cells transiently expressing apoE plasmids. Neuro-2a cells were transfected with apoE3, apoE3-SP, or apoE+NLS-SP plasmids, and nuclei were isolated after $12 \mathrm{hr}$ of expression. Nuclei were processed for apoE immunoreactivity as described in Materials and Methods. There are several hundred nuclei present in each of the three panels, yet only those nuclei that contain apoE are illuminated. Inset shows a high-magnification view of one of the apoE-positive nuclei isolated from Neuro-2a cells transiently expressing apoE3+NLS. The images were collected by confocal microscopy with a $20 \times$ objective. Scale bars, $50 \mu \mathrm{m}$. Inset was collected with a $60 \times$ oil immersion lens. Scale bar (in inset), $5 \mu \mathrm{m}$.

apoE3+NLS disks showed an equivalent accumulation of fulllength apoE3 and apoE3+NLS (data not shown).

\section{Endocytosed apoE does not escape into the cytosol}

Parental Neuro-2a cells were incubated in the presence of varying concentrations of apoE3 lipoproteins for $4 \mathrm{hr}$. After washing the

\section{Neuro-2a + ApoE3}
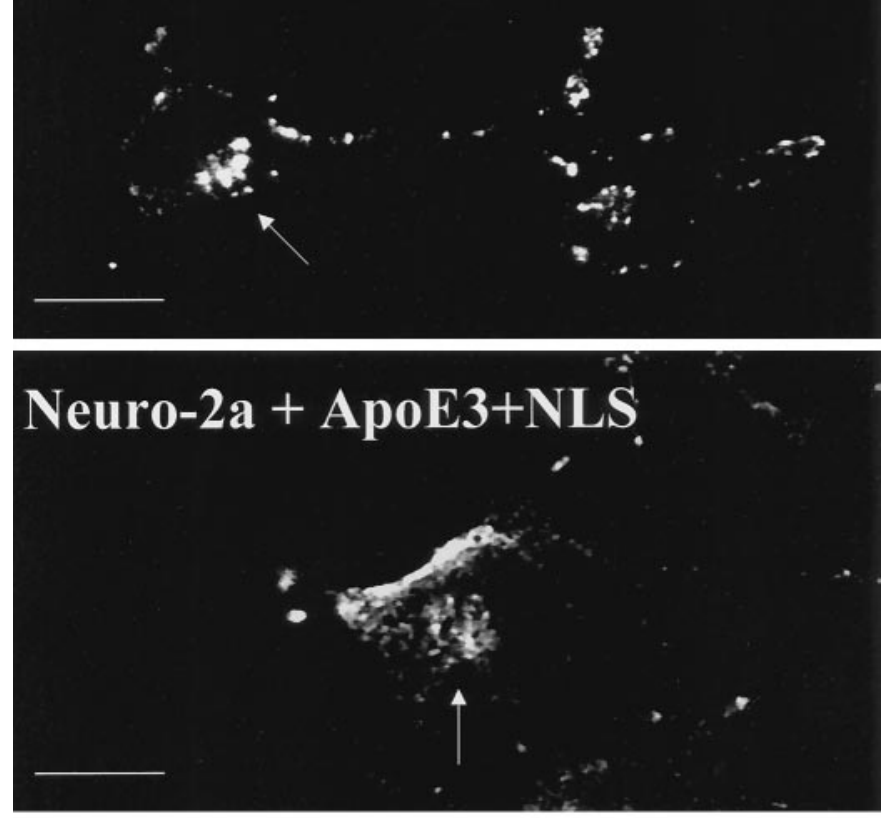

\section{Neuro-2a Control}

Figure 7. Immunocytochemical localization of endocytosed apoE disks. ApoE3 and apoE3+NLS were isolated from conditioned media and recombined with dimyristoyl-phosphatidylcholine to form lipoprotein disks. Neuro-2a cells were incubated with lipoprotein disks for $4 \mathrm{hr}$, and the endocytosed apoE was identified by immunocytochemistry. Control cells lacked the addition of the apoE lipoproteins. ApoE localization was detected with an affinity-purified polyclonal goat anti-human apoE antibody and a rhodamine-conjugated secondary antibody. The endocytosed apoE appears to be highly localized within membrane vesicles in a perinuclear compartment that may be indicative of neuronal lysosomes (arrows). All images were collected by confocal microscopy with a $60 \times$ oil immersion lens. Scale bars, $20 \mu \mathrm{m}$.

cells and removing cell surface apoE by trypsin digestion, the cells were fractionated into cytoplasmic (all intracellular constituents except nuclei) and nuclear fractions. A sensitive ELISA was used to determine the apoE content of each fraction. The cytoplasmic fraction contained membrane-bound apoE (endosomallysosomal), whereas the nuclear fraction contained any apoE that escaped to the cytosol.

To ensure the repeatability of the nuclear localization assay, we performed two identical experiments on separate days with two independent apoE particle preparations (Table 2, experiments A, B). Neuro-2a cells in duplicate plates were incubated for $4 \mathrm{hr}$ with either apoE3 or apoE3 + NLS disks at a concentration of 10 $\mu \mathrm{g} / \mathrm{ml}$ and were processed as described above. In both experi- 


\begin{tabular}{|c|c|c|c|c|c|c|}
\hline Experiment & ApoE particle & $\begin{array}{l}\text { Intracellular E3 } \\
\text { (ng/mg cell protein) }\end{array}$ & $\begin{array}{l}\text { Intracellular E3 }+ \text { NLS } \\
(\mathrm{ng} / \mathrm{mg} \text { cell protein })\end{array}$ & $\begin{array}{l}\text { ApoE cleared } \\
\text { from medium }\end{array}$ & Percent cleared & $\begin{array}{l}\text { Nuclear } \\
\text { apoE }\end{array}$ \\
\hline A & Discs $10 \mu \mathrm{g} / \mathrm{ml}$ & $179.5 \pm 2.2$ & $143.3 \pm 15.9$ & $4.1 \mu \mathrm{g}$ & $41 \%$ & $\mathrm{ND}$ \\
\hline B & Discs $10 \mu \mathrm{g} / \mathrm{ml}$ & $111.2 \pm 17$ & $137.8 \pm 9.1$ & $4.3 \mu \mathrm{g}$ & $43 \%$ & ND \\
\hline $\mathrm{C}$ & Discs $25 \mu \mathrm{g} / \mathrm{ml}$ & $692.8 \pm 147$ & $784.1 \pm 337$ & - & - & ND \\
\hline $\mathrm{D}$ & $\begin{array}{l}\text { Discs } 10 \mu \mathrm{g} / \mathrm{ml} \text { plus lipid } \\
\text { poor apoE } 10 \mu \mathrm{g} / \mathrm{ml}\end{array}$ & $147.5 \pm 6.7$ & $151.7 \pm 12.5$ & $12.3 \mu \mathrm{g}$ & $62 \%$ & ND \\
\hline $\mathrm{E}$ & ApoE $\beta$ VLDL $10 \mu \mathrm{g} / \mathrm{ml}$ & $52.8 \pm 7.0$ & $17.9 \pm 2.2$ & - & - & ND \\
\hline $\mathrm{F}$ & $\begin{array}{l}\text { Mouse } \beta \text { VLDL plus lipid } \\
\text { poor apoE } 10 \mu \mathrm{g} / \mathrm{ml}\end{array}$ & $52.3 \pm 0.2$ & $21.9 \pm 2.3$ & $8.2 \mu \mathrm{g}$ & $82 \%$ & ND \\
\hline
\end{tabular}

ND, Not detected.

ments, similar levels of apoE3 and apoE3+NLS were found in cytoplasmic extracts. There was minimal variation in endocytosis of apoE between particle preparations. No nuclear apoE was detected in either experiment, thereby indicating that no detectable apoE escaped the endocytic pathway. We analyzed the culture medium after the $4 \mathrm{hr}$ incubation to determine the degree of apoE clearance. We observed substantial clearance of apoE3 and apoE3+NLS during the incubation period (an average of $42 \%$ of total apoE added was cleared). The clearance value (42\%) is the sum of degraded apoE, extracellularly associated apoE, and apoE detected in the cell. Neuro-2a cells have been shown to have the capacity to degrade large quantities of lipoproteins during short incubation periods (Bellosta et al., 1995; Ji et al., 1998).

We next tested whether increasing particle uptake would result in cytosolic apoE. Neuro-2a cells were incubated with $25 \mu \mathrm{g} / \mathrm{ml}$ apoE3 or apoE3 + NLS disks, and the subcellular location of the endocytosed apoE was determined (Table 2, experiment C). Although there was a fivefold increase in the amount of apoE found within the cytoplasmic extracts, nuclear apoE was not detected. Because lipoprotein uptake has been reported to be enhanced by the addition of lipid-free apoE (Ji et al., 1998), Neuro-2a cells were incubated with apoE3 or apoE3 + NLS disks supplemented with $10 \mu \mathrm{g} / \mathrm{ml}$ lipid-poor apoE3 or apoE3+NLS, respectively (Table 2, experiment D). Although there was an increase in the percent of apoE cleared from the culture media (from 42 to 62\%), the levels of endosomal-lysosomal apoE were unchanged, and no nuclear apoE was detected.

We next asked whether the use of different endocytic pathways could result in the escape of apoE to the cytosol. Because lipoprotein size has been shown to be a determining factor for receptor specificity (Tabas et al., 1991), we incorporated apoE3 and apoE3 + NLS into large $\beta$ VLDL from apoE knock-out mice. The particles were prepared by incubating lipid-poor apoE3 or apoE3 + NLS with plasma from apoE knock-out mice and subsequently isolating the apoE3- $\beta$ VLDL or apoE3+NLS- $\beta$ VLDL by ultracentrifugation $(\rho<1.006)$. The purified particles were then used in our standard $4 \mathrm{hr}$ nuclear localization assay at a concentration of $10 \mu \mathrm{g} / \mathrm{ml}$ (apoE). ApoE3- $\beta$ VLDL and apoE3+NLS$\beta$ VLDL accumulated in the intracellular vesicles to a lesser extent than the apoE disks (Table 2, experiment E) and were absent from the nuclear compartment. We observed similar results when lipid-poor apoE was simply added to cells along with apoE knock-out mouse $\beta$ VLDL (Table 2 , experiment F). In this case, there was a very high level of apoE clearance from the culture medium ( $82 \%$ of total apoE). The results presented in Table 2 indicate that intracellular apoE is not localized to the cytosol but is retained within the membrane vesicles of the endosomal-lysosomal pathway.

\section{DISCUSSION}

Determining the validity of the cytosolic apoE hypothesis is critical for evaluating the physiological significance of apoE-tau interactions and understanding the risk factor association of apoE and Alzheimer's disease (Strittmatter et al., 1994b). We designed a novel nuclear localization assay to test whether apoE can access the cytosol via the endocytic pathway. During initial characterization of Neuro-2a stable cell lines, we discovered that direct apoE expression in the cytosol might be cytotoxic. Cytosolic apoE toxicity was confirmed when stable transfection efficiency experiments revealed that there were 30 -fold fewer colonies for cytosolic apoE3 compared with secreted apoE3. This finding was further substantiated by the detection of cytosolic apoE in cells transiently expressing the signal peptide bypass plasmids. The discovery of the apoE3 cytosolic toxicity diminishes the possibility that apoE3 would be protective in the cytosol. However, the threshold concentration for cytosolic apoE toxicity is unknown.

We used transient transfection and expression of the signal peptide bypass plasmids to verify that the cell recognizes the NLS in apoE. Immunocytochemical results demonstrate that the incorporated NLS was recognized, because the apoE3+NLS was actively chaperoned to the nuclei of Neuro-2a cells. Additionally, we showed that the diffuse cytosolic staining pattern of apoE3-SP was easily differentiated from that of the vesiclebound apoE3. ApoE immunocytochemical studies in human brain sections showed apoE immunoreactivity within a population of neural cells (Han et al., 1994; Metzger et al., 1996). Although the authors speculate that this immunoreactivity represents a cytosolic localization, the actual data are inconclusive. This reactivity may be caused by the accumulation of apoE within neural endosomes and lysosomes because neurons express many receptors that bind apoE containing lipoproteins (Pitas et al., 1987b; Schneider et al., 1997). The question that was not addressed was whether any of this intracellular apoE was cytosolic. The most compelling evidence to support the apoE cytosolic hypothesis is an immunofluorescence study showing the colocalization of endocytosed apoE and tau (Lovestone et al., 1996). COS-7 cells transiently over-expressing human LDL receptor and tau were incubated with either apoE3 or apoE4 CSF lipoproteins and were analyzed by immunocytochemistry. The results show that a substantial fraction of the intracellular apoE3 colocalizes with the over-expressed tau (therefore speculated to be cytosolic), whereas apoE4 does not. What is not clear in this study is whether 
this colocalization is caused by the massive accumulation of apoE3-bearing vesicles in close proximity to the microtubular arrays. A recent report (Ji et al., 1998) emphasizes the possibility that colocalization is an artifact. ApoE3 accumulates intracellularly to a greater extent than apoE4 in several different cell lines. The over expression of the LDL receptor in COS-7 cells may have exaggerated this difference and led to the massive accumulation of apoE3 vesicles, making the immunofluorescence colocalization difficult to interpret. It is interesting to note that the diffuse immunofluorescence pattern observed with direct expression of apoE in the cytosol (Fig. $4 B$ ) is very different from the punctate staining that has been interpreted as cytosolic apoE in numerous studies (Han et al., 1994; Strittmatter et al., 1994b; Nathan et al., 1995; Ji et al., 1998).

Our sensitive nuclear localization assay demonstrates that apoE does not appear to escape the endocytic pathway at a detectable level in a neuroblastoma cell line. This assay quantitatively measures the subcellular localization of endocytosed apoE and apoE+NLS. A murine neuroblastoma cell line (Neuro2a) was used for these experiments because our group and others have shown previously that the Neuro-2a cells exhibit apoE isoform-specific differences in neurite outgrowth (Bellosta et al., 1995; Nathan et al., 1995; DeMattos et al., 1998). We showed immunocytochemically and by ELISA that an equivalent amount of apoE3 and apoE3+NLS disks were endocytosed. Neuro-2a cells were incubated with either apoE3 or apoE3+NLS disks, and the resulting intracellular localization of the endocytosed apoE was determined by ELISA. The endocytic values do not include cell surface-bound apoE (this fraction was removed by trypsin digestion before subcellular fractionation). In every experiment performed, we detected similar levels of apoE3 or apoE3 + NLS in the fraction containing endosomes and lysosomes, yet we were unable to detect any apoE3+NLS in the nuclear fractions (Table 2). The same result was attained whether we added a higher concentration of apoE disks to the culture medium or supplemented the disks with lipid-poor apoE. The levels of intracellular apoE are comparable to those reported previously for uptake by Neuro-2a cells (Ji et al., 1998). These experiments demonstrate that, to the level of our detection, endocytosed apoE remains within the vesicle-bound intracellular pathways and does not escape into the cytosolic compartment.

The sensitivity of the nuclear localization assay is determined by two factors: the overall amount of apoE endocytosed and the sensitivity of detection of apoE within the nuclear fraction. The ELISA can readily detect $5 \mathrm{ng}$ of apoE/mg of cell protein. Based on these considerations, the sensitivity for detecting apoE in the nuclear fraction can be assessed in two ways. In the first, the detection limit can be compared with the steady-state level of apoE within the cell. For example, in Table 2, experiments A, B, $\mathrm{C}$, and $\mathrm{D}$, the assay could have detected $3.5,3.5,0.7$, and $3 \%$, respectively, of the steady-state apoE within the cell. By this measurement, if as little as $0.7 \%$ of the apoE within the endocytic pathway had escaped to the cytosol (experiment $\mathrm{C}$ ), it could have been detected in the nuclear fraction. The sensitivity would have been less in experiments $\mathrm{E}$ and $\mathrm{F}$ because of the lower levels of cellular apoE.

In the second, the detection limit can be compared with the amount of apoE cleared from the medium, which is a reflection of the cumulative amount of apoE processed by the endocytic pathway during the assay. Because our assay procedure removed cell surface and extracellular matrix apoE by trypsin treatment, the values for apoE clearance from the medium must be corrected for these factors. Using the very conservative estimate that only $15 \%$ of the cleared apoE was processed and degraded by the endosomal-lysosomal pathway in the $4 \mathrm{hr}$ assay with Neuro-2a cells (Bellosta et al., 1995, Ji et al., 1998), the nuclear localization assay could have detected $0.7,0.7$, and $0.25 \%$ of the apoE processed by the endocytic pathway in experiments $\mathrm{A}, \mathrm{B}$, and $\mathrm{D}$, respectively (Table 2). These results indicate that $>99.5 \%$ (if not all) of the intracellular apoE is retained within the membrane-bound compartments of the endosomal-lysosomal pathways and does not escape to the cytosolic compartment.

Our final experiments indicate that, regardless of the endocytic receptor system targeted, apoE does not escape into the cytosol. Preliminary Western blot studies indicate that Neuro-2a cells express the low-density lipoprotein receptor, the very low-density lipoprotein receptor, and the low-density lipoprotein receptorrelated protein (R. B. DeMattos, D. K. Strickland, and D. L. Williams, unpublished observations); further studies will determine whether Neuro-2a cells express other members of the LDL receptor super family. We performed nuclear localization experiments with apoE3 or apoE3 + NLS that were associated with $\beta$ VLDL from apoE knockout mice. Literature reports highlight the importance of particle size and composition for determining the apoE receptor specificity. The apolipoprotein $E$ receptor 2 (a predominately brain-specific receptor) has been shown to have a higher affinity for apoE- $\beta$ VLDL as opposed to the smaller VLDL or LDL particles (Kim et al., 1996). Additionally, the LDL receptor-related protein was demonstrated to have a higher binding affinity for $\beta$ VLDL in the presence of exogenously added lipid-free apoE (Kowal et al., 1989, 1990). Both $\beta$ VLDL experiments shown in Table 2 indicate that a lower steady-state level of intracellular apoE was attained by the conclusion of the $4 \mathrm{hr}$ assay, yet the amount of total apoE cleared from the media was enhanced $(82 \%)$ compared with the apoE disk experiments. These results suggest that a different receptor pathway processed the larger apoE- $\beta$ VLDL particles. We were unable to detect any apoE3+NLS in the nuclear fractions in either of these assays, indicating that intracellular apoE remained in vesicles and was not accessible to the nuclear localization machinery.

Our results demonstrate that the vast majority of endocytosed apoE does not gain access to the cytosolic compartment of Neuro-2a cells. It is important to note that the Neuro-2a cells have been shown by two independent groups to develop apoE isoform-specific neurite outgrowth differences under the same culture conditions as in this study. These results indicate that the isoform-specific stimulation of neurite outgrowth is unlikely to be caused by apoE in the cytosol. More likely, apoE alters neurite outgrowth via an unknown isoform-specific mechanism originating at the cell surface. Possible mechanisms could be receptormediated signaling cascades or an apoE-dependent cell matrix adhesion event. There is suggestive evidence for each of these possibilities in the literature (Misra et al., 1994; Hjalm et al., 1996; Park and Wright, 1996; Huang et al., 1995).

\section{REFERENCES}

Bellosta S, Nathan BP, Orth M, Dong L-M, Mahley RW, Pitas RE (1995) Stable expression and secretion of apolipoprotein E3 and E4 in mouse neuroblastoma cells produces differential effects on neurite outgrowth. J Biol Chem 270:27063-27071.

Blue M-L, Williams DL, Zucker S, Khan SA, Blum CB (1983) Apolipoprotein E synthesis in human kidney, adrenal gland, and liver. Proc Natl Acad Sci USA 80:283-287.

Bottenstein JE, Sato GH (1979) Growth of a rat neuroblastoma cell line 
in serum-free supplemented medium. Proc Natl Acad Sci USA 76:514-517.

Boyles JK, Pitas RE, Wilson E, Mahley RW, Taylor JM (1985) Apolipoprotein $\mathrm{E}$ associated with astrocytic glia of the central nervous system and with nonmyelinating glia of the peripheral nervous system. J Clin Invest 76:1501-1513.

Boyles JK, Notterpek LM, Anderson LJ (1990) Accumulation of apolipoproteins in the regenerating and remyelinating mammalian peripheral nerve. Identification of apolipoprotein D, apolipoprotein A-IV, apolipoprotein E, and apolipoprotein A-I. J Biol Chem 265:17805-17815.

Chen C, Okayama H (1987) High-efficiency transformation of mammalian cells by plasma DNA. Mol Cell Biol 7:2745-2752.

Dawson PA, Schechter N, Williams DL (1986) Induction of rat E and chicken A-1 apolipoproteins and mRNAs during optic nerve degeneration. J Biol Chem 261:5681-5684.

DeMattos RB, Curtiss LK, Williams DL (1998) A minimally-lipidated form of cell-derived apolipoprotein E exhibits isoform-specific stimulation of neurite outgrowth in the absence of exogenous lipids or lipoproteins. J Biol Chem 273:4206-4212.

Dingwall C, Laskey RA (1991) Nuclear targeting sequences-a consensus? Trends Biochem Sci 16:478-481.

Elshourbagy NA, Liao WS, Mahley RW, Taylor JM (1985) Apolipoprotein E mRNA is abundant in the brain and adrenal, as well as in the liver and is present in other peripheral tissues of rats and marmosets. Proc Natl Acad Sci USA 82:203-207.

Goedert M, Strittmatter W, Roses A (1994) Risky apolipoprotein in brain. Nature 372:45-46.

Han S-H, Einstein G, Weisgraber KH, Strittmatter WJ, Saunders AM, Pericak-Vance M, Roses AD, Schmechel DE (1994) Apolipoprotein $\mathrm{E}$ is localized to the cytoplasm of human cortical neurons: a light and electron microscopic study. J Neuropathol Exp Neurol 53:535-544.

Hjalm G, Murray E, Crumley G, Harazim W, Lundgren S, Onyango I, Ek B, Larsson M, Juhlin C, Hellman P, Davis H, Akerstrom G, Rask L, Morse B (1996) Cloning and sequencing of human gp330, a $\mathrm{Ca}^{2+}$ binding receptor with potential intracellular signaling properties. J Biol Chem 239:132-137.

Holtzman DM, Pitas RE, Kilbridge J, Nathan B, Mahley RW, Bu G, Schwartz AL (1995) Low density lipoprotein receptor-related protein mediates apolipoprotein E-dependent neurite outgrowth in a central nervous system-derived neuronal cell line. Proc Natl Acad Sci USA 92:9480-9484.

Huang DY, Weisgraber KH, Strittmatter WJ, Matthew WD (1995) Interaction of apolipoprotein $\mathrm{E}$ with laminin increases neuronal adhesion and alters neurite morphology. Exp Neurol 136:251-257.

Ignatius MJ, Gebickle-Harter PJ, Skene JHP, Schilling JW, Weisgraber KH, Mahley RW, Shooter EM (1986) Expression of apolipoprotein E during nerve degeneration and regeneration. Proc Natl Acad Sci USA 83:1125-1129.

Ignatius MJ, Shooter EM, Pitas RE, Mahley RW (1987) Lipoprotein uptake by neuronal growth cones in vitro. Science 236:959-962.

Innerarity TL, Pitas RE, Mahley RW (1979) Binding of arginine-rich (E) apoprotein after recombination with phospholipid vesicles to the low density lipoprotein receptors of fibroblasts. $J$ Biol Chem 254:4186-4190.

Ji Z, Pitas RE, Mahley RW (1998) Differential cellular accumulation/ retention of apolipoprotein $\mathrm{E}$ mediated by cell surface heparan sulfate proteoglycans. J Biol Chem 273:13452-13460.

Kelly JL, Kruski AW (1986) Density gradient ultracentrifugation of serum lipoproteins in a swinging bucket rotor. Methods Enzymol 128:170-181.

Kim D, Iijima H, Goto K, Sakai J, Ishii H, Kim H, Suzuki H, Kondo H, Saeki S, Yamamoto T (1996) Human apolipoprotein E receptor 2. J Biol Chem 271:8373-8380.

Kowal RC, Herz J, Goldstein JL, Esser V, Brown MS (1989) Low density lipoprotein receptor-related protein mediates uptake of cholesteryl esters derived from apoprotein E-enriched lipoproteins. Proc Natl Acad Sci USA 86:5810-5814.

Kowal RC, Herz J, Weisgraber KH, Mahley RW, Brown MS, Goldstein JL (1990) Opposing effects of apolipoproteins E and C on lipoprotein binding to low density lipoprotein receptor-related protein. J Biol Chem 265:10771-10779.

Kozak M (1986) Point mutations define a sequence flanking the AUG initiator codon that modulates translation by eukaryotic ribosomes. Cell 44:283-292.
LaDu MJ, Falduto MT, Manelli AM, Reardon CA, Getz GS, Frail DE (1994) Isoform-specific binding of apolipoprotein $\mathrm{E}$ to $\beta$-amyloid. J Biol Chem 269:23403-23406.

LaDu MJ, Pederson TM, Frail DE, Reardon CA, Getz GS, Falduto MT (1995) Purification of apolipoprotein $\mathrm{E}$ attenuates isoform-specific binding to $\beta$-amyloid. J Biol Chem 270:9039-9042.

Lovestone S, Anderton BH, Hartley C, Jensen TG, Jorgensen AL (1996) The intracellular fate of apolipoprotein $\mathrm{E}$ is tau- dependent and apoE allele-specific. NeuroReport 7:1005-1008.

Lowry OH, Rosebrough NJ, Farr AL, Randall RJ (1951) Protein measurement with the folin phenol reagent. J Biol Chem 193:265-275.

Metzger RE, LaDu MJ, Pan JB, Getz GS, Frail DE, Falduto MT (1996) Neurons of the human frontal cortex display apolipoprotein E immunoreactivity: implications for Alzheimer's disease. J Neuropathol Exp Neurol 55:372-380.

Mirra SS, Heyman A, McKeel D, Sumi SM, Crain BJ, Brownlee LM, Vogel FS, Hughes JP, van Belle G, Berg L (1991) The consortium to establish a registry for Alzheimer's disease (CERAD). II. Standardization of the neuropathologic assessment of Alzheimer's disease. Neurology 41:479-486.

Misra UK, Chu CT, Gawdi G, Pizzo SV (1994) The relationship between low density lipoprotein-related protein/alpha 2-macroglobulin (alpha 2M) receptors and the newly described alpha $2 \mathrm{M}$ signaling receptor. J Biol Chem 269:18303-18306.

Nakai M, Kawamata T, Maeda K, Tanaka C (1996) Expression of apoE mRNA in rat microglia. Neurosci Lett 211:41-44.

Nathan BP, Bellosta S, Sanan DA, Weisgraber KH, Mahley RW, Pitas RE (1994) Differential effects of apolipoproteins E3 and E4 on neuronal growth in vitro. Science 264:850-852.

Nathan BP, Chang K-C, Bellosta S, Brisch E, Ge N, Mahley RW, Pitas RE (1995) The inhibitory effect of apolipoprotein E4 on neurite outgrowth is associated with microtubule depolymerization. J Biol Chem 270:19797-19799.

Newman TC, Dawson PA, Rudel LL, Williams DL (1985) Quantitation of apolipoprotein E messenger RNA in the liver and peripheral tissues of nonhuman primates. J Biol Chem 260:2452-2457.

Park CT, Wright SD (1996) Plasma lipopolysaccharide-binding protein is found associated with a particle containing apolipoprotein A-I, phospholipid, and factor H-related proteins. J Biol Chem 271:18054-18060.

Pitas RE, Boyles JK, Lee SH, Foss D, Mahley RW (1987a) Astrocytes synthesize apolipoprotein $\mathrm{E}$ and metabolize apolipoprotein E-containing lipoproteins. Biochim Biophys Acta 917:148-161.

Pitas RE, Boyles JK, Lee SH, Hui D, Weisgraber KH (1987b) Lipoproteins and their receptors in the central nervous system. J Biol Chem 262:14352-14360.

Rea TJ, DeMattos RB, Pape ME (1993) Hepatic expression of genes regulating lipid metabolism in rabbits. J Lipid Res 34:1901-1910.

Rebeck GW, Reiter JS, Strickland DK, Hyman BT (1993) Apolipoprotein $\mathrm{E}$ in sporadic Alzheimer's disease: allelic variation and receptor interactions. Neuron 11:575-580.

Roberts BL, Richardson WD, Smith AE (1987) The effect of protein context on nuclear location signal function. Cell 50:465-475.

Schneider WJ, Nimpf J, Bujo H (1997) Novel members of the low density lipoprotein receptor superfamily and their potential roles in lipid metabolism. Curr Opin Lipidol 8:315-319.

Silver PA (1991) How proteins enter the nucleus. Cell 64:489-497.

Snipes GJ, McGuire CB, Norden JJ, Freeman JA (1986) Nerve injury stimulates the secretion of apolipoprotein E by nonneuronal cells. Proc Natl Acad Sci USA 83:1130-1134.

Stone DJ, Rozovsky I, Morgan TE, Anderson CP, Hajian H, Finch CE (1997) Astrocytes and microglia respond to estrogen with increased apoE mRNA in vivo and in vitro. Exp Neurol 143:313-318.

Strittmatter WJ, Saunders AM, Schmechel D, Pericak-Vance M, Enghild J, Salvessen GS, Roses AD (1993a) Apolipoprotein E: high-avidity binding to $\beta$-amyloid and increased frequency of type 4 allele in late-onset familial Alzheimer's disease. Proc Natl Acad Sci USA 90:1977-1981.

Strittmatter WJ, Weisgraber KH, Huang DY, Dong L-M, Salvessen GS, Pericak-Vance M, Schmechel D, Saunders AM, Goldgaber D, Roses AD (1993b) Binding of human apolipoprotein $E$ to synthetic amyloid $\beta$ peptide: isoform-specific effects and implications for late-onset Alzheimer's disease. Proc Natl Acad Sci USA 90:8098-8102.

Strittmatter WJ, Saunder AM, Goedert M, Weisgraber KH, Dong LM, Jakes R, Huang DY, Pericak-Vance M, Schmechel D, Roses AD 
(1994a) Isoform-specific interactions of apolipoprotein $\mathrm{E}$ with microtubule-associated protein tau: implications for Alzheimer's disease. Proc Natl Acad Sci USA 91:11183-11186.

Strittmatter WJ, Weisgraber K, Goedert M, Saunders A, Huang D, Corder E, Dong L-M, Jakes R, Alberts M, Gilbert J, Han S-H, Hulette C, Einstein G, Schmechel D, Pericak-Vance M, Roses A (1994b) Hypothesis: microtubule instability and paired helical filament formation in the Alzheimer's disease brain are related to apolipoprotein $\mathrm{E}$ genotype. Exp Neurol 125:163-171.

Sun Y, Wu S, Bu G, Onifade MK, Patel SN, LaDu MJ, Fagan AM, Holtzman DM (1998) Glial fibrillary acidic protein-apolipoprotein E (apoE) transgenic mice: astrocyte-specific expression and differing biological effects of astrocyte-secreted apoE3 and apoE4 lipoproteins. J Neurosci 18:3261-3272.

Tabas I, Myers JN, Innerarity TL, Xu X-X, Arnold K, Boyles J, Maxfield
FR (1991) The influence of particle size and multiple apoprotein E-receptor interactions on the endocytic targeting of $\beta$-VLDL in mouse peritoneal macrophages. J Cell Biol 115:1547-1560.

Weis K, Mattaj IW, Lamond AI (1995) Identification of hSRP1 $\beta$ as a functional receptor for nuclear localization sequences. Science 268:1049-1053.

Weisgraber KH (1994) Apolipoprotein E: structure-function relationships. Adv Protein Chem 45:249-302.

Williams DL, Dawson PA, Newman TC, Rudel LL (1985) Apolipoprotein $\mathrm{E}$ synthesis in peripheral tissues of nonhuman primates. J Biol Chem 260:2444-2451.

Zannis VI, Breslow JL, Utermann G, Mahley RW, Weisgraber KH, Havel RJ, Goldstein JL, Brown MS, Schonfeld G, Hazzard WR, Blum C (1982) Proposed nomenclature of apoE isoproteins, apoE genotypes, and phenotypes. J Lipid Res 23:911-914. 